\title{
Efficacy and safety of canagliflozin compared with placebo in older patients with type 2 diabetes mellitus: a pooled analysis of clinical studies
}

Alan Sinclairr* ${ }^{\text {** }}$ Bruce Bode ${ }^{2}$, Stewart Harris ${ }^{3}$, Ujjwala Vijapurkar ${ }^{4}$, Cristiana Mayer $^{5}$, Albert Fung ${ }^{4}$, Wayne Shaw ${ }^{4}$, Keith Usiskin ${ }^{4}$, Mehul Desai ${ }^{4}$ and Gary Meininger ${ }^{4}$

\begin{abstract}
Background: Canagliflozin is a sodium glucose co-transporter 2 inhibitor developed for the treatment of patients with type 2 diabetes mellitus (T2DM). The efficacy and safety of canagliflozin were evaluated in patients with $\mathrm{T} 2 \mathrm{DM}<65$ and $\geq 65$ years of age.

Methods: Pooled data from 4 randomised, placebo-controlled, 26-week, Phase 3 studies ( $N=2,313)$ evaluating canagliflozin 100 and 300 mg were analysed by age: $<65$ years ( $n=1,868$; mean age, 52.8 years) or $\geq 65$ years ( $n=445$; mean age, 69.3 years). Efficacy evaluations included change from baseline in glycaemic parameters and systolic blood pressure (BP), and percent change from baseline in body weight. Assessment of safety/tolerability included adverse event (AE) reports, incidence of documented hypoglycaemia, and percent change from baseline in fasting plasma lipids.

Results: Canagliflozin 100 and $300 \mathrm{mg}$ reduced $\mathrm{HbA}_{1 \mathrm{c}}$ and fasting plasma glucose relative to placebo in patients $<65$ and $\geq 65$ years of age. Both canagliflozin doses reduced body weight and systolic BP relative to placebo in patients $<65$ and $\geq 65$ years of age. Incidence of overall AEs was similar across all treatment groups in patients $<65$ and $\geq 65$ years of age. Incidences of serious AEs and AE-related discontinuations were similar across all treatment groups in patients $<65$ years of age and higher with canagliflozin $100 \mathrm{mg}$ than other groups in patients $\geq 65$ years of age. As in patients $<65$ years of age, incidences of genital mycotic infections and osmotic diuresis-related AEs were higher with canagliflozin relative to placebo in those $\geq 65$ years of age. Incidences of urinary tract infections (UTIS), renal-related AEs, AEs related to volume depletion, and documented hypoglycaemia episodes were similar across all treatment groups in patients $\geq 65$ years of age; no notable trends were observed with canagliflozin 100 and $300 \mathrm{mg}$ relative to placebo in these AEs among patients $<65$ years of age. Changes in lipid parameters with canagliflozin were similar in both age subsets.
\end{abstract}

Conclusions: Canagliflozin improved glycaemic control, body weight, and systolic BP, and was generally well tolerated in older patients with T2DM.

Trial registration: ClinicalTrials.gov, NCT01081834; NCT01106677; NCT01106625; NCT01106690.

Keywords: Canagliflozin, Type 2 diabetes mellitus, Sodium glucose co-transporter 2 (SGLT2) inhibitor, Antihyperglycaemic agent, Older patients

\footnotetext{
* Correspondence: Alan.Sinclair@beds.ac.uk

'Luton \& Dunstable University Hospital; Bedfordshire and Hertfordshire Postgraduate Medical School, University of Bedfordshire, Putteridge Bury Campus, Hitchin Road, Luton LU2 8LE, UK

Full list of author information is available at the end of the article
} 


\section{Background}

Advancing age, the increased prevalence of medical comorbidities, and the emergence of frailty can impact the selection of antihyperglycaemic agent (AHA) therapies for treating older patients with type 2 diabetes mellitus (T2DM) [1,2]. Important safety considerations in this population include those related to renal or hepatic impairment, cardiovascular disease, polypharmacy, and self-management ability [1,3-5]. Hypoglycaemia is of particular concern for older patients with T2DM because the risk of experiencing a hypoglycaemia episode increases with advancing age [5,6]; hypoglycaemia episodes associated with AHA use are a major cause of hospitalisations among older patients with T2DM [7]. Thus, the benefit/risk profiles of available AHA therapies are important considerations in treating older patients with T2DM.

Canagliflozin is a sodium glucose co-transporter 2 (SGLT2) inhibitor developed for the treatment of patients with T2DM [8-16]. Canagliflozin lowers the renal threshold for glucose excretion $\left(\mathrm{RT}_{\mathrm{G}}\right)$ and increases urinary glucose excretion (UGE) in individuals with hyperglycaemia, resulting in decreased plasma glucose as well as an osmotic diuresis and net caloric loss $[8,17,18]$. In Phase 3 studies in patients with T2DM, canagliflozin has been shown to improve glycaemic control and reduce body weight and blood pressure (BP) as monotherapy or in combination with a variety of background AHAs [9-16].

In a Phase 3 study of older patients with T2DM $\geq 55$ to $\leq 80$ years of age, canagliflozin 100 and $300 \mathrm{mg}$ significantly reduced $\mathrm{HbA}_{1 \mathrm{c}}$, fasting plasma glucose (FPG), body weight, and systolic BP relative to placebo, and were generally well tolerated [11]. Incidences of genital mycotic infections, urinary tract infections (UTIs), and osmotic diuresis-related adverse events (AEs) were higher with canagliflozin than placebo, consistent with findings from other studies of canagliflozin in generally younger patient populations $[9,10,12,14-16]$. To further evaluate the efficacy and safety of canagliflozin in older patients with T2DM, an analysis of pooled data from 4 randomised, placebo-controlled, Phase 3 studies (the aforementioned study in older patients was not included in this pooled analysis) was performed, with results reported for subsets of patients $<65$ and $\geq 65$ years of age.

\section{Methods}

\section{Study design and patient population}

This pooled analysis evaluated canagliflozin 100 and $300 \mathrm{mg}$ and placebo using data from subsets of patients with T2DM $<65$ and $\geq 65$ years of age from 4 randomised, double-blind, placebo-controlled, Phase 3 studies. These studies each included a 26-week, double-blind, core treatment period and a 26-week extension period, and assessed canagliflozin as monotherapy [9] or added on to metformin [14], metformin plus sulphonylurea [15], and metformin plus pioglitazone (Table 1). Data from the 26-week core treatment periods of each study were included in this pooled analysis; the high glycaemic subset $\left(\mathrm{HbA}_{1 \mathrm{c}}>10.0 \%\right.$ and $\leq 12.0 \%$ ) of the monotherapy study, which was not placebo controlled, and the sitagliptin arm of the add-on to metformin study were excluded. For the pooled dataset, the mean duration of exposure to study drug was approximately 24 weeks in each treatment group.

Key inclusion criteria for the individual studies are summarised in Table 1. In general, eligible patients were those with $\mathrm{T} 2 \mathrm{DM} \geq 18$ and $\leq 80$ years of age, with $\mathrm{HbA}_{1 \mathrm{c}} \geq 7.0 \%$ and $\leq 10.5 \%$ and estimated glomerular filtration rate (eGFR) $\geq 55 \mathrm{~mL} / \mathrm{min} / 1.73 \mathrm{~m}^{2}$ at screening. Key exclusion criteria that were common across studies included repeated FPG $\geq 15.0 \mathrm{mmol} / \mathrm{L}$ during the pretreatment phase; history of type 1 diabetes; history of cardiovascular (CV) disease (including myocardial infarction, unstable angina, revascularisation procedure, or cerebrovascular accident) within 3 months prior to screening; and alanine aminotransferase (ALT) level $>2.0$ times the upper limit of normal (ULN) or total bilirubin $>1.5$ the ULN at screening.

In each study, eligible patients who were on protocolspecified background diabetes treatment directly entered a 2-week, placebo run-in period; those not on protocolspecified background diabetes therapy entered an 8- to

Table 1 Summary of patient populations

\begin{tabular}{|c|c|c|c|c|c|c|c|c|c|}
\hline \multirow{3}{*}{ Study } & \multirow{3}{*}{ Duration $^{*}$} & \multicolumn{3}{|c|}{ Inclusion criteria } & \multicolumn{5}{|c|}{ Patients contributing to pooled analysis, $n$} \\
\hline & & Age, y & $\mathrm{HbA}_{1 \mathrm{c}} \%$ & eGFR, & PBO & CANA & CANA & Total & Aged \\
\hline & & & & $\mathrm{mL} / \mathrm{min} / 1.73 \mathrm{~m}^{2}$ & & $100 \mathrm{mg}$ & $300 \mathrm{mg}$ & & $\geq 65 y$ \\
\hline Monotherapy & 26 weeks & $\geq 18$ to $\leq 80$ & $\geq 7.0$ and $\leq 10.0$ & $\geq 50$ & 192 & 195 & 197 & 584 & 118 \\
\hline Add-on to MET & 26 weeks & $\geq 18$ to $\leq 80$ & $\geq 7.0$ and $\leq 10.5$ & $\geq 55$ & 183 & 368 & 367 & 918 & 149 \\
\hline Add-on to MET + SU & 26 weeks & $\geq 18$ to $\leq 80$ & $\geq 7.0$ and $\leq 10.5$ & $\geq 55$ & 156 & 157 & 156 & 469 & 85 \\
\hline Add-on to MET + PIO & 26 weeks & $\geq 18$ to $\leq 80$ & $\geq 7.0$ and $\leq 10.5$ & $\geq 55$ & 115 & 113 & 114 & 342 & 93 \\
\hline Overall total, $\mathrm{n}$ & & & & & 646 & 833 & 834 & 2,313 & 445 \\
\hline
\end{tabular}

eGFR, estimated glomerular filtration rate; PBO, placebo; CANA, canagliflozin; MET, metformin; SU, sulphonylurea; PIO, pioglitazone.

*Assessment time point; mean treatment exposure of $24.2,24.3$, and 23.8 weeks with canagliflozin 100 and 300 mg and placebo, respectively. 
12-week AHA adjustment/dose stabilisation period prior to the run-in period. Patients were to remain on their stable diabetes treatment regimen through the end of the double-blind treatment period. Randomisation to treatment group (canagliflozin 100 or $300 \mathrm{mg}$ or placebo) was stratified to ensure adequate distribution of specific patient characteristics (eg, whether a patient entered the AHA adjustment/dose stabilisation period) across treatment groups. After randomisation, $\mathrm{HbA}_{1 \mathrm{c}}$ and $\mathrm{FPG}$ were masked to study centres unless pre-defined criteria for initiation of glycaemic rescue therapy based on $\mathrm{HbA}_{1 \mathrm{c}}$ or FPG values were met. Study databases were locked at the primary assessment time point (Week 26) and studies were unblinded by the sponsor for regulatory filing. Blinding was maintained for patients and study centre and local sponsor personnel throughout the doubleblind treatment period.

Glycaemic rescue therapy was initiated during the double-blind treatment period for patients who met prespecified criteria (in general, FPG $>15.0 \mathrm{mmol} / \mathrm{L}$ after Day 1 to Week $6,>13.3 \mathrm{mmol} / \mathrm{L}$ after Week 6 to Week 12 , and $>11.1 \mathrm{mmol} / \mathrm{L}$ after Week 12 to Week 26). The agent for rescue therapy in each study was selected to be complementary to the protocol-specified background AHA therapy.

The studies were conducted in accordance with the ethical principles that comply with the Declaration of Helsinki, and are consistent with Good Clinical Practices and applicable regulatory requirements. Approval was obtained from institutional review boards and independent ethics committees for participating centres (Additional file 1), and patients gave written informed consent prior to participation.

\section{Endpoints and assessments}

Efficacy endpoints evaluated at Week 26 included change from baseline in $\mathrm{HbA}_{1 \mathrm{c}}$, FPG, and systolic and diastolic $\mathrm{BP}$, and percent change from baseline in body weight (reported for prior to rescue medication).

Assessments of overall safety and tolerability were based on AEs, safety laboratory tests, 12-lead electrocardiograms, vital sign measurements, physical examinations, and selfmonitored blood glucose. The incidence of selected AEs, including UTIs, genital mycotic infections, AEs related to osmotic diuresis and volume depletion, and renal-related AEs, were also evaluated. Documented hypoglycaemia episodes included biochemically confirmed episodes (concurrent fingerstick or plasma glucose $\leq 3.9 \mathrm{mmol} / \mathrm{L}$, with or without symptoms) and severe episodes (ie, those requiring the assistance of another individual or resulting in seizure or loss of consciousness).

Percent changes from baseline in fasting plasma lipids, including triglycerides, high-density lipoprotein cholesterol (HDL-C), low-density lipoprotein cholesterol (LDL-C),
LDL-C/HDL-C ratio, and non-HDL-C, were assessed as safety parameters.

\section{Statistical analyses}

Efficacy endpoints were analysed in the modified intentto-treat (mITT) population consisting of randomised patients who received $\geq 1$ dose of study drug. The last observation carried forward (LOCF) approach was used to impute missing efficacy data. For patients who received rescue therapy, the last post-baseline value prior to initiation of rescue therapy was used for efficacy analyses. Changes from baseline in efficacy parameters at Week 26 were assessed using an analysis of covariance (ANCOVA) model including treatment and study as fixed effects and baseline values as covariates. Least squares (LS) means and 2 -sided $95 \%$ confidence intervals (CIs) were estimated for the comparisons of each canagliflozin dose versus placebo. Fasting plasma lipid parameters were assessed in the safety analysis set (identical to the mITT population) using a similar ANCOVA model as for efficacy endpoints. Statistical testing of comparisons of canagliflozin versus placebo within each age group, and of comparisons between age groups, was not conducted (not pre-specified). Therefore, no $P$ values are reported; however, $95 \%$ CIs are provided.

\section{Results}

\section{Patient disposition and baseline characteristics}

Of the patients in the pooled population who were randomised and dosed, $85.9 \%$ and $85.4 \%$ of those $<65$ and $\geq 65$ years of age, respectively, completed the 26-week treatment period. A higher proportion of patients in the placebo group compared with the combined canagliflozin group discontinued before the Week 26 visit among patients $<65$ years of age $(18.2 \%$ vs $12.6 \%)$ and those $\geq 65$ years of age (17.5\% vs $13.3 \%)$. Baseline demographic and disease characteristics were generally similar across treatment groups within each age subset (Table 2). Patients $\geq 65$ years of age had a lower mean baseline eGFR, a longer mean duration of T2DM, and a higher proportion with cardiac disorders and on antihypertensive medication compared with the $<65$ years subset.

\section{Efficacy \\ Glycaemic parameters}

Canagliflozin 100 and $300 \mathrm{mg}$ reduced $\mathrm{HbA}_{1 \mathrm{c}}$ compared with placebo in patients $<65$ and $\geq 65$ years of age (Figure 1A). Placebo-subtracted $\mathrm{HbA}_{1 \mathrm{c}}$ reductions with canagliflozin 100 and $300 \mathrm{mg}$ were $-0.7 \%$ and $-0.9 \%$, respectively, in patients $<65$ years of age, and $-0.6 \%$ and $-0.8 \%$ in those $\geq 65$ years of age. At Week 26 , the proportion of patients $<65$ years of age achieving $\mathrm{HbA}_{1 \mathrm{c}}<7.0 \%$ was $45.6 \%, 60.0 \%$, and $23.7 \%$ with canagliflozin 100 and $300 \mathrm{mg}$ and placebo, respectively; $42.8 \%, 57.5 \%$, and $28.5 \%$ 
Table 2 Baseline demographic and disease characteristics ${ }^{*}$

\begin{tabular}{|c|c|c|c|c|c|c|}
\hline \multirow[b]{2}{*}{ Characteristic } & \multicolumn{3}{|c|}{ Patients $<65 \mathrm{y}$} & \multicolumn{3}{|c|}{ Patients $\geq 65 \mathrm{y}$} \\
\hline & $\begin{array}{l}\text { PBO } \\
(n=509)\end{array}$ & $\begin{array}{l}\text { CANA } 100 \mathrm{mg} \\
(\mathrm{n}=674)\end{array}$ & $\begin{array}{l}\text { CANA } 300 \mathrm{mg} \\
(\mathrm{n}=685)\end{array}$ & $\begin{array}{l}\text { PBO } \\
(n=137)\end{array}$ & $\begin{array}{l}\text { CANA } 100 \mathrm{mg} \\
(\mathrm{n}=159)\end{array}$ & $\begin{array}{l}\text { CANA } 300 \mathrm{mg} \\
(\mathrm{n}=149)\end{array}$ \\
\hline \multicolumn{7}{|l|}{ Sex, n (\%) } \\
\hline Male & $263(51.7)$ & $327(48.5)$ & $327(47.7)$ & $71(51.8)$ & $81(50.9)$ & $77(51.7)$ \\
\hline Female & $246(48.3)$ & $347(51.5)$ & $358(52.3)$ & $66(48.2)$ & $78(49.1)$ & $72(48.3)$ \\
\hline Age, y & $53.0 \pm 8.1$ & $52.6 \pm 8.1$ & $52.8 \pm 7.8$ & $68.7 \pm 3.5$ & $70.0 \pm 3.6$ & $69.1 \pm 3.5$ \\
\hline \multicolumn{7}{|l|}{ Race, $\mathrm{n}(\%)^{\dagger}$} \\
\hline White & $358(70.3)$ & $455(67.5)$ & $482(70.4)$ & $112(81.8)$ & $136(85.5)$ & $128(85.9)$ \\
\hline Black or African American & $23(4.5)$ & $40(5.9)$ & $43(6.3)$ & $5(3.6)$ & $3(1.9)$ & $5(3.4)$ \\
\hline Asian & $75(14.7)$ & $99(14.7)$ & $92(13.4)$ & $7(5.1)$ & $4(2.5)$ & $8(5.4)$ \\
\hline Other $^{\ddagger}$ & $53(10.4)$ & $80(11.9)$ & $68(9.9)$ & $13(9.5)$ & $16(10.1)$ & $8(5.4)$ \\
\hline $\mathrm{HbA}_{1 \mathrm{c}} \%$ & $8.1 \pm 1.0$ & $8.0 \pm 0.9$ & $8.0 \pm 1.0$ & $7.8 \pm 0.8$ & $7.9 \pm 0.9$ & $7.9 \pm 0.9$ \\
\hline $\mathrm{FPG}, \mathrm{mmol} / \mathrm{L}$ & $9.3 \pm 2.2$ & $9.4 \pm 2.3$ & $9.4 \pm 2.3$ & $9.0 \pm 2.1$ & $9.6 \pm 2.4$ & $9.6 \pm 2.6$ \\
\hline Body weight, kg & $90.1 \pm 22.3$ & $91.0 \pm 22.7$ & $89.3 \pm 22.8$ & $86.3 \pm 19.4$ & $84.6 \pm 19.7$ & $84.6 \pm 17.7$ \\
\hline $\mathrm{BMI}, \mathrm{kg} / \mathrm{m}^{2}$ & $32.2 \pm 6.7$ & $32.7 \pm 6.6$ & $32.3 \pm 6.7$ & $30.8 \pm 5.0$ & $30.8 \pm 5.2$ & $30.5 \pm 5.2$ \\
\hline Systolic BP, mmHg & $127.4 \pm 13.2$ & $126.9 \pm 12.6$ & $127.6 \pm 12.6$ & $132.7 \pm 13.1$ & $132.5 \pm 12.8$ & $134.3 \pm 12.5$ \\
\hline eGFR, mL/min/1.73 m² & $90.0 \pm 19.9$ & $90.9 \pm 19.0$ & $91.3 \pm 18.9$ & $75.9 \pm 15.1$ & $77.3 \pm 14.6$ & $77.4 \pm 13.5$ \\
\hline Duration of diabetes, $y$ & $6.7 \pm 5.4$ & $6.4 \pm 5.2$ & $6.7 \pm 5.4$ & $10.2 \pm 7.9$ & $10.5 \pm 7.0$ & $10.8 \pm 8.1$ \\
\hline Patients with cardiac disorders, $\mathrm{n}(\%)^{\S}$ & $64(12.6)$ & $85(12.6)$ & $87(12.7)$ & $39(28.5)$ & $46(28.9)$ & $45(30.2)$ \\
\hline Patients on antihypertensive medications, $\mathrm{n}(\%)^{\|}$ & $305(59.9)$ & $415(61.6)$ & $408(59.6)$ & $110(80.3)$ & $120(75.5)$ & $115(77.2)$ \\
\hline
\end{tabular}

PBO, placebo; CANA, canagliflozin; FPG, fasting plasma glucose; BMI, body mass index; BP, blood pressure; eGFR, estimated glomerular filtration rate; SD, standard deviation; MedDRA, Medical Dictionary for Regulatory Activities.

*Data are mean \pm SD unless otherwise indicated.

${ }^{\dagger}$ Percentages may not total $100.0 \%$ due to rounding.

${ }^{\ddagger}$ Includes American Indian or Alaska Native, Native Hawaiian or other Pacific Islander, multiple, other, unknown, and not reported.

${ }^{\S}$ Defined based on the MedDRA v13.1 system organ class for cardiac disorders from medical history.

IIncludes agents acting on the renin-angiotensin system, $\beta$-blocking agents, calcium channel blockers, and diuretics.

of patients $\geq 65$ years of age achieved $\mathrm{HbA}_{1 \mathrm{c}}<7.0 \%$ with canagliflozin 100 and $300 \mathrm{mg}$ and placebo, respectively. Canagliflozin 100 and $300 \mathrm{mg}$ also reduced FPG compared with placebo in both age subsets (Figure 1B). The effect of canagliflozin in lowering FPG was greater in patients $<65$ years of age (placebo-subtracted reductions for canagliflozin 100 and $300 \mathrm{mg}$ of -1.7 and $-2.2 \mathrm{mmol} / \mathrm{L}$, respectively, in patients $<65$ years of age, and -1.2 and $-1.9 \mathrm{mmol} / \mathrm{L}$, respectively, in patients $\geq 65$ years of age).

\section{Body weight and $B P$}

Canagliflozin 100 and $300 \mathrm{mg}$ provided reductions in body weight in patients $<65$ and $\geq 65$ years of age (Figure 1C), with differences versus placebo of $-2.2 \%$ and $-2.8 \%$, respectively, in patients <65 years of age and $-2.3 \%$ and $-3.2 \%$, respectively, in those $\geq 65$ years of age. Both canagliflozin doses were associated with reductions in systolic and diastolic BP in both age subsets (Figures 1D and $1 \mathrm{E}$ ). For systolic BP, placebo-subtracted reductions were $-3.9 \mathrm{mmHg}$ with canagliflozin $100 \mathrm{mg}$ in both age subsets, and -4.5 and $-5.1 \mathrm{mmHg}$ with canagliflozin $300 \mathrm{mg}$ in patients $<65$ and $\geq 65$ years of age, respectively. Changes in diastolic BP with canagliflozin 100 and $300 \mathrm{mg}$ were greater in patients $\geq 65$ years of age (placebo-subtracted reductions of -2.6 and $-2.5 \mathrm{mmHg}$, respectively) than in those $<65$ years of age $(-1.8 \mathrm{mmHg}$ for both doses). Mean changes in pulse rate with canagliflozin 100 and $300 \mathrm{mg}$ and placebo were $-0.9,-0.1$, and 0.2 beats per minute (bpm), respectively, in patients $<65$ years of age and $0.6,-1.8$, and $-0.9 \mathrm{bpm}$, respectively, in those $\geq 65$ years of age.

\section{Safety and tolerability Overall safety and tolerability}

The overall incidence of AEs was similar with canagliflozin and placebo within and across age subsets (Table 3). Incidences of serious AEs and AEs leading to discontinuation were low $(\leq 3.3 \%)$ and similar across groups in patients $<65$ years of age. In patients $\geq 65$ years of age, higher incidences of serious AEs and AE-related discontinuations were observed with canagliflozin $100 \mathrm{mg}$ (6.9\% 
A

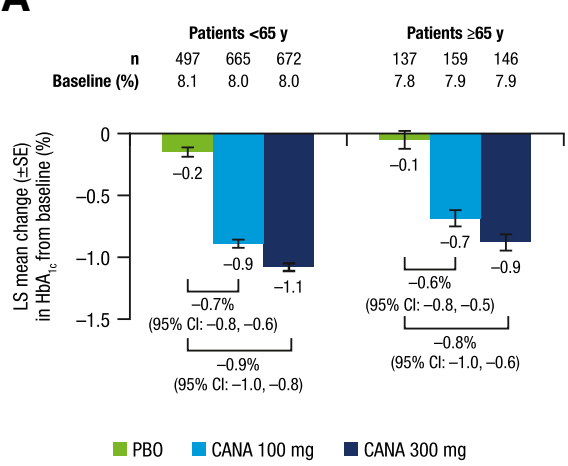

C
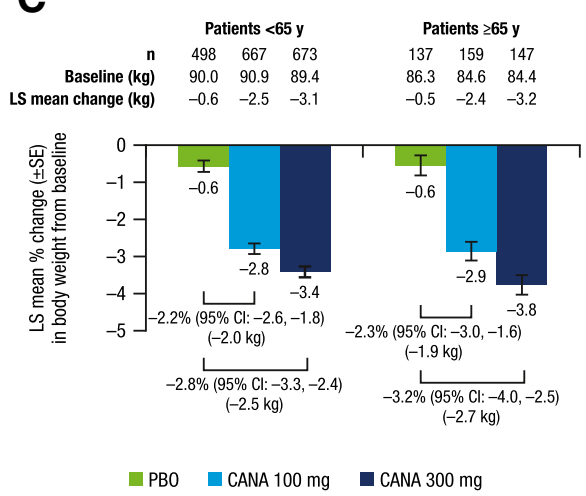

E
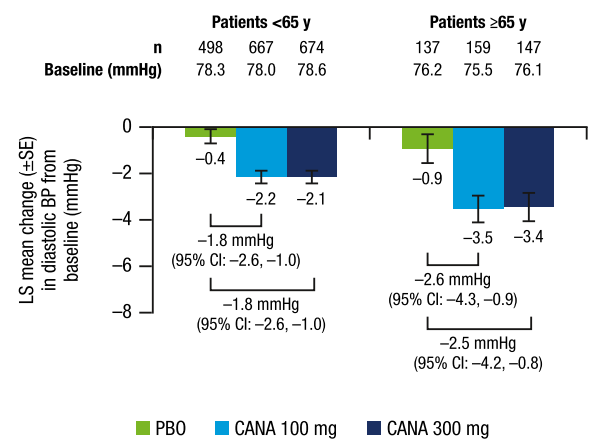

B

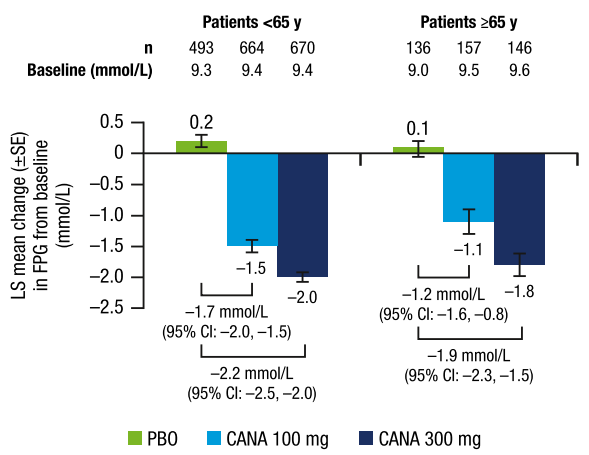

D
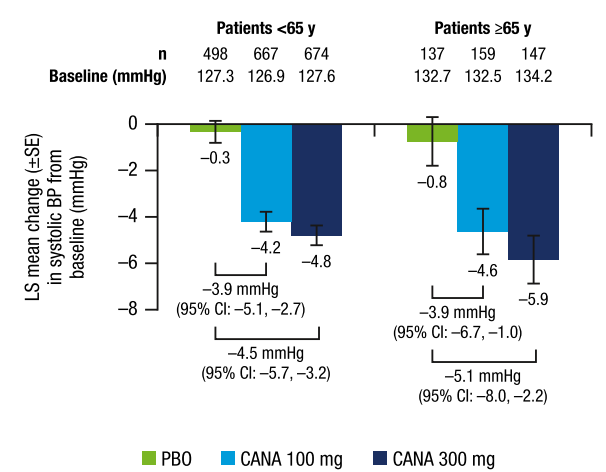

Figure 1 Changes in efficacy parameters (LOCF). (A) Change in $\mathrm{HbA}_{1,}$ (B) change in $\mathrm{FPG}$, (C) percent change in body weight, (D) change in systolic BP, and (E) change in diastolic BP. LOCF, last observation carried forward; FPG, fasting plasma glucose; BP, blood pressure; LS, least squares; $\mathrm{SE}$, standard error; $\mathrm{Cl}$, confidence interval; PBO, placebo; CANA, canagliflozin.

and $8.8 \%$, respectively) relative to canagliflozin $300 \mathrm{mg}$ (3.4\% and $5.4 \%$, respectively) and placebo (3.6\% and $4.4 \%$, respectively); these increases with canagliflozin $100 \mathrm{mg}$ were not associated with any pattern in specific AEs. Relative to placebo, both canagliflozin doses were associated with a higher incidence of AEs related to study drug in patients $<65$ and $\geq 65$ years of age, which were mainly related to the specific AEs discussed below.

Canagliflozin 100 and $300 \mathrm{mg}$ were associated with increased incidence of genital mycotic infections in males and females relative to placebo in patients in both age subsets. Incidence of genital mycotic infections was no greater in patients $\geq 65$ years of age compared with those $<65$ years of age (Table 3). No serious genital mycotic infection AEs were reported and most were mild or moderate in intensity, as assessed by the investigator. Among female patients, 5 genital mycotic infection AEs led to study discontinuation in the $<65$ years subset (4 with canagliflozin $100 \mathrm{mg}$ and 1 with canagliflozin $300 \mathrm{mg}$ ), and 1 led to study discontinuation in the $\geq 65$ years subset (canagliflozin $300 \mathrm{mg}$ ). Two male canagliflozin-treated patients discontinued from the 
Table 3 Summary of overall safety and selected AEs*

\begin{tabular}{|c|c|c|c|c|c|c|}
\hline & \multicolumn{3}{|c|}{ Patients <65 y, n (\%) } & \multicolumn{3}{|c|}{ Patients $\geq 65 \mathrm{y}, \mathrm{n}(\%)$} \\
\hline & $\begin{array}{l}\text { PBO } \\
(n=509)\end{array}$ & $\begin{array}{l}\text { CANA } 100 \mathrm{mg} \\
(\mathrm{n}=674)\end{array}$ & $\begin{array}{l}\text { CANA } 300 \mathrm{mg} \\
(\mathrm{n}=685)\end{array}$ & $\begin{array}{l}\text { PBO } \\
(n=137)\end{array}$ & $\begin{array}{l}\text { CANA } 100 \mathrm{mg} \\
(\mathrm{n}=159)\end{array}$ & $\begin{array}{l}\text { CANA } 300 \mathrm{mg} \\
(\mathrm{n}=149)\end{array}$ \\
\hline Any $A E$ & $300(58.9)$ & $404(59.9)$ & $404(59.0)$ & $84(61.3)$ & $97(61.0)$ & $90(60.4)$ \\
\hline AEs leading to discontinuation & $14(2.8)$ & $22(3.3)$ & $22(3.2)$ & $6(4.4)$ & $14(8.8)$ & $8(5.4)$ \\
\hline AEs related to study drug ${ }^{\dagger}$ & $66(13.0)$ & $136(20.2)$ & $155(22.6)$ & $19(13.9)$ & $35(22.0)$ & $36(24.2)$ \\
\hline Serious AEs & $17(3.3)$ & $17(2.5)$ & $17(2.5)$ & $5(3.6)$ & $11(6.9)$ & $5(3.4)$ \\
\hline Deaths & $1(0.2)$ & $1(0.1)$ & $1(0.1)$ & $1(0.7)$ & 0 & 0 \\
\hline \multicolumn{7}{|l|}{ Selected AEs } \\
\hline UTI & $20(3.9)$ & $41(6.1)$ & $29(4.2)$ & $6(4.4)$ & $8(5.0)$ & $7(4.7)$ \\
\hline \multicolumn{7}{|l|}{ Genital mycotic infection } \\
\hline Male $e^{\ddagger \S}$ & $2(0.8)$ & $14(4.3)$ & $11(3.4)$ & 0 & $3(3.7)$ & $4(5.2)$ \\
\hline Female $e^{\|, \AA}$ & $10(4.1)$ & $37(10.7)$ & $44(12.3)$ & 0 & $7(9.0)$ & $5(6.9)$ \\
\hline Osmotic diuresis-related AEs ${ }^{\#}$ & $4(0.8)$ & $44(6.5)$ & $39(5.7)$ & $1(0.7)$ & $12(7.5)$ & $8(5.4)$ \\
\hline Volume depletion-related AEs ${ }^{* *}$ & $5(1.0)$ & $6(0.9)$ & $8(1.2)$ & $2(1.5)$ & $4(2.5)$ & $3(2.0)$ \\
\hline Renal-related $\mathrm{AEs}^{\dagger+}$ & $2(0.4)$ & $2(0.3)$ & $12(1.8)$ & $2(1.5)$ & $3(1.9)$ & $2(1.3)$ \\
\hline
\end{tabular}

$\mathrm{AE}$, adverse event; $\mathrm{PBO}$, placebo; CANA, canagliflozin; UTI, urinary tract infection.

${ }^{*}$ All AEs are reported for regardless of rescue medication; hypoglycaemia episodes are reported for prior to rescue medication.

${ }^{\dagger}$ Possibly, probably, or very likely related to study drug, as assessed by investigators.

${ }^{\ddagger}$ For patients $<65$ years: PBO, $\mathrm{n}=263$; CANA $100 \mathrm{mg}, \mathrm{n}=327$; CANA $300 \mathrm{mg}, \mathrm{n}=327$; for patients $\geq 65$ years: PBO, $\mathrm{n}=71 ; \mathrm{CANA} 100 \mathrm{mg}, \mathrm{n}=81$; CANA $300 \mathrm{mg}, \mathrm{n}=77$.

${ }^{\S}$ Reported terms included balanitis, balanitis candida, balanoposthitis, and genital infection fungal in both age groups.

"For patients <65 years: PBO, $n=246$; CANA $100 \mathrm{mg}, \mathrm{n}=347$; CANA $300 \mathrm{mg}, \mathrm{n}=358$; for patients $\geq 65$ years: PBO, $\mathrm{n}=66 ;$; CANA 100 mg, $\mathrm{n}=78$; CANA $300 \mathrm{mg}, \mathrm{n}=72$.

"Reported terms included vaginal infection, vulvovaginal candidiasis, vulvovaginal mycotic infection, and vulvovaginitis in both age groups, and genital infection fungal and vulvitis in patients aged $<65$ years.

"Reported terms included micturition urgency, nocturia, pollakiuria, polyuria, dry mouth, polydipsia, and thirst in both age groups, and urine output increased in patients aged $<65$ years.

${ }^{* *}$ Reported terms included dizziness postural, hypotension, and orthostatic hypotension in both age groups, and dehydration and syncope in patients aged $<65$ years.

${ }^{+\dagger}$ Reported terms included blood creatinine increased, glomerular filtration rate decreased, and renal impairment in both age groups, and renal failure acute in patients aged $<65$ years.

study due to genital mycotic infections in each age subset (both with canagliflozin $300 \mathrm{mg}$ in the $<65$ years subset and both with canagliflozin $100 \mathrm{mg}$ in the $\geq 65$ years subset). The incidence of UTIs was higher with canagliflozin $100 \mathrm{mg}$ relative to canagliflozin $300 \mathrm{mg}$ and placebo in patients $<65$ years of age and similar across groups in those $\geq 65$ years of age. Two serious UTIs were reported in patients $<65$ years of age ( 1 with canagliflozin $100 \mathrm{mg}$ and 1 with canagliflozin $300 \mathrm{mg}$ ) and 1 UTI led to study discontinuation in the placebo group. No UTIs were serious or led to study discontinuation in patients $\geq 65$ years of age.

A higher incidence of AEs related to osmotic diuresis (eg, pollakiuria [increased urination frequency], polyuria [increased urine volume]) was seen with canagliflozin relative to placebo in patients $<65$ and $\geq 65$ years of age, with similar incidences observed in the 2 age subsets. Most AEs related to osmotic diuresis were mild or moderate in intensity, as assessed by the investigator, and none were serious; 3 patients experienced osmotic diuresisrelated AEs that led to study discontinuation (1 with canagliflozin $100 \mathrm{mg}$ and 2 with canagliflozin $300 \mathrm{mg}$ ), all in patients $<65$ years of age. The incidence of volume depletion-related AEs (eg, postural dizziness, orthostatic hypotension) was low ( $\leq 2.5 \%)$ across treatment groups in both age subsets. In patients $<65$ years of age, the incidence of volume depletion-related AEs was similar with canagliflozin 100 and $300 \mathrm{mg}$ and placebo $(0.9 \%, 1.2 \%$, and $1.0 \%$, respectively). Although there were few patients $\geq 65$ years of age with volume depletion-related AEs, there was a trend toward a higher incidence with canagliflozin 100 and $300 \mathrm{mg}$ relative to placebo $(2.5 \%$, $2.0 \%$, and $1.5 \%$, respectively). Most volume depletionrelated AEs were mild or moderate in intensity, as assessed by the investigator. There was 1 serious volume depletion-related AE and 1 event that led to study discontinuation, both in the placebo group in 2 distinct patients $<65$ years of age.

A low incidence $(<2 \%)$ of renal-related AEs (eg, glomerular filtration rate decreased, renal impairment) was seen in patients $\geq 65$ years of age that was similar across treatment groups $(1.9 \%, 1.3 \%$, and $1.5 \%$ with 
canagliflozin 100 and $300 \mathrm{mg}$ and placebo, respectively); a higher incidence was observed with canagliflozin $300 \mathrm{mg}$ relative to canagliflozin $100 \mathrm{mg}$ and placebo in patients $<65$ years of age $(1.8 \%, 0.3 \%$ and $0.4 \%$, respectively). Most renal-related AEs were mild or moderate in intensity, as assessed by the investigator, for patients $<65$ years of age, except for 1 serious renal-related AE with canagliflozin $100 \mathrm{mg}$. Overall, 10 patients discontinued due to renal-related AEs with canagliflozin, 6 patients $<65$ years of age (all with canagliflozin $300 \mathrm{mg}$ ), and 4 patients $\geq 65$ years of age ( 3 with canagliflozin $100 \mathrm{mg}$ and 1 with canagliflozin $300 \mathrm{mg}$ ); a renal-related AE led to study discontinuation in 1 patient $\geq 65$ years of age with placebo.

Early transient decreases from baseline in eGFR were seen with canagliflozin within the first 3 to 6 weeks of treatment, which subsequently were stable or attenuated over the 26-week treatment period. At Week 26, canagliflozin 100 and $300 \mathrm{mg}$ were associated with mean percent decreases in eGFR relative to placebo in patients $<65$ years of age $(-1.6 \%,-3.0 \%$, and $-0.6 \%$, respectively) and those $\geq 65$ years of age $(-2.6 \%,-2.9 \%$, and $-0.4 \%$, respectively).

Among patients who were not on background sulphonylurea therapy (ie, excluding those from the add-on to metformin plus sulphonylurea study), the incidence of documented hypoglycaemia episodes with canagliflozin 100 and $300 \mathrm{mg}$ and placebo was $4.1 \%, 4.0 \%$, and 3.6\%, respectively, in patients $\geq 65$ years of age $(n=360)$; in those $<65$ years of age $(n=1,484)$, the incidence was $3.8 \%, 4.3 \%$, and $1.8 \%$, respectively. Canagliflozin was not associated with an increase in the incidence of severe hypoglycaemia episodes, with 2 events reported in patients $<65$ years of age ( 1 in each canagliflozin group) and none in patients $\geq 65$ years of age. A total of 384 patients $<65$ years of age and 85 patients $\geq 65$ years of age were on background sulphonylurea (ie, patients from the add-on to metformin plus sulphonylurea study); in these patients, the incidence of documented hypoglycaemia episodes with canagliflozin 100 and $300 \mathrm{mg}$ and placebo was $27.8 \%, 26.1 \%$, and $11.5 \%$, respectively, in patients $\geq 65$ years of age and $27.3 \%$, $30.8 \%$, and $16.2 \%$, respectively, in patients $<65$ years of age. In patients on background sulphonylurea, there were no severe hypoglycaemia episodes reported in patients $\geq 65$ years of age, and 2 severe hypoglycaemia episodes were reported in patients $<65$ years of age ( 1 with placebo and 1 with canagliflozin $100 \mathrm{mg}$ ).

\section{Fasting plasma lipids}

Overall, changes in lipid parameters with canagliflozin compared with placebo were generally similar in patients $<65$ and $\geq 65$ years of age (Table 4). Increases in HDL-C were seen with canagliflozin 100 and $300 \mathrm{mg}$ relative to placebo in both age subsets (differences vs placebo of $5.2 \%$ and $6.1 \%$, respectively, in patients $<65$ years of age, and $6.2 \%$ and $7.2 \%$, respectively, in patients $\geq 65$ years of age). Canagliflozin 100 and $300 \mathrm{mg}$ were associated with increases in LDL-C relative to placebo in both age subsets (differences vs placebo of $4.8 \%$ and $8.3 \%$, respectively, in patients $<65$ years of age, and $2.7 \%$ and $6.1 \%$, respectively, in patients $\geq 65$ years of age), with increases in non-HDL-C that were smaller than those seen in LDL-C. Relative to placebo, there were no meaningful changes in triglycerides or the LDL-C/HDL-C ratio with canagliflozin in both age subsets.

\section{Discussion}

The treatment of older patients with T2DM must take into consideration factors specific to these patients, including the increased prevalence of comorbidities and use of concomitant medications, with patient safety being a priority $[1,19]$. For example, safety issues related to available AHAs that may be of particular concern in older patients include gastrointestinal intolerability and contraindication in patients with renal impairment for metformin; risk of congestive heart failure and fracture with thiazolidinediones; and risk of hypoglycaemia with sulphonylureas and insulin [5]. In this analysis, the efficacy and safety of canagliflozin were evaluated using pooled data from patients with T2DM $<65$ and $\geq 65$ years of age. Canagliflozin 100 and $300 \mathrm{mg}$ improved glycaemic control relative to placebo in patients $<65$ and $\geq 65$ years of age, with a slightly greater effect observed in patients aged $<65$ years relative to those aged $\geq 65$ years. Canagliflozin provided reductions in body weight and systolic and diastolic BP compared with placebo in both age subsets. Canagliflozin was generally well tolerated, with higher incidences relative to placebo of genital mycotic infections and osmotic diuresis-related AEs in both age subsets. Findings in this analysis were consistent with those from previous studies, including one in older patients $\geq 55$ to $\leq 80$ years of age [9-16].

A slightly numerically lesser effect of canagliflozin in lowering $\mathrm{HbA}_{1 \mathrm{c}}$ and FPG was observed in patients $\geq 65$ years of age relative to those $<65$ years of age, which may be related to the lower mean baseline $\mathrm{HbA}_{1 \mathrm{c}}$ and eGFR in older patients. The mechanism of action of canagliflozin is through induction of UGE, the rate of which is dependent on plasma glucose concentration and GFR [20-22]; thus, the effect of canagliflozin in increasing UGE is expected to be attenuated in patients with lower eGFR. For example, canagliflozin improved glycaemic control to a lesser extent in patients with moderate renal impairment (eGFR $\geq 30$ and $<50 \mathrm{~mL} / \mathrm{min} / 1.73 \mathrm{~m}^{2}$ [13]) relative to patients with normal or mildly impaired renal function $[9,10,12]$. Consistent with this, reductions in $\mathrm{HbA}_{1 \mathrm{c}}$ and FPG with canagliflozin in the previous study in older patients [11] were 
Table 4 Summary of changes from baseline in fasting plasma lipids at Week 26 (LOCF)

\begin{tabular}{|c|c|c|c|c|c|c|}
\hline & \multicolumn{3}{|c|}{ Patients $<65 \mathrm{y}$} & \multicolumn{3}{|c|}{ Patients $\geq 65 \mathrm{y}$} \\
\hline & PBO & CANA $100 \mathrm{mg}$ & CANA $300 \mathrm{mg}$ & PBO & CANA $100 \mathrm{mg}$ & CANA $300 \mathrm{mg}$ \\
\hline Triglycerides, $\mathrm{n}$ & 446 & 614 & 610 & 118 & 139 & 131 \\
\hline Mean \pm SD baseline, $\mathrm{mmol} / \mathrm{L}$ & $2.2 \pm 1.4$ & $2.1 \pm 1.5$ & $2.1 \pm 1.5$ & $1.8 \pm 0.8$ & $1.9 \pm 1.1$ & $1.7 \pm 0.9$ \\
\hline LS mean \pm SE change & $0.01 \pm 0.05$ & $-0.10 \pm 0.04$ & $-0.23 \pm 0.04$ & $-0.05 \pm 0.05$ & $-0.14 \pm 0.05$ & $-0.16 \pm 0.05$ \\
\hline \multirow[t]{2}{*}{ Median (IQR) percent change } & -1.6 & -6.0 & -9.3 & -3.2 & -7.4 & -9.2 \\
\hline & $(-22.1,28.8)$ & $(-26.4,24.4)$ & $(-28.6,19.8)$ & $(-20.4,16.3)$ & $(-21.9,10.6)$ & $(-25.8,10.2)$ \\
\hline LS mean \pm SE percent change & $9.1 \pm 2.2$ & $3.7 \pm 2.0$ & $0.6 \pm 2.0$ & $2.6 \pm 3.0$ & $-2.4 \pm 2.8$ & $-2.5 \pm 2.9$ \\
\hline Difference versus PBO (95\% Cl) & & $-5.4(-11.1,0.3)$ & $-8.5(-14.2,-2.8)$ & & $-5.0(-13.0,3.1)$ & $-5.1(-13.3,3.1)$ \\
\hline LDL-C, n & 444 & 609 & 601 & 118 & 137 & 129 \\
\hline Mean \pm SD baseline, $\mathrm{mmol} / \mathrm{L}$ & $2.9 \pm 1.0$ & $2.8 \pm 0.9$ & $2.7 \pm 0.9$ & $2.7 \pm 1.0$ & $2.6 \pm 0.9$ & $2.7 \pm 1.0$ \\
\hline LS mean \pm SE change & $-0.05 \pm 0.03$ & $0.06 \pm 0.03$ & $0.17 \pm 0.03$ & $-0.07 \pm 0.06$ & $0.04 \pm 0.05$ & $0.07 \pm 0.06$ \\
\hline \multirow[t]{2}{*}{ Median (IQR) percent change } & -2.3 & 2.0 & 6.5 & -1.5 & 1.9 & 2.0 \\
\hline & $(-16.9,11.3)$ & $(-10.7,19.4)$ & $(-7.8,23.9)$ & $(-9.8,12.2)$ & $(-7.1,15.5)$ & $(-10.5,17.9)$ \\
\hline $\mathrm{LS}$ mean \pm SE percent change & $1.5 \pm 1.4$ & $6.3 \pm 1.2$ & $9.8 \pm 1.2$ & $0.7 \pm 2.1$ & $3.5 \pm 1.9$ & $6.8 \pm 2.0$ \\
\hline Difference versus PBO (95\% Cl) & & $4.8(1.2,8.4)$ & $8.3(4.7,11.9)$ & & $2.7(-2.9,8.4)$ & $6.1(0.4,11.8)$ \\
\hline $\mathrm{HDL}-\mathrm{C}, \mathrm{n}$ & 446 & 612 & 606 & 118 & 138 & 129 \\
\hline Mean \pm SD baseline, $\mathrm{mmol} / \mathrm{L}$ & $1.2 \pm 0.3$ & $1.2 \pm 0.3$ & $1.2 \pm 0.3$ & $1.2 \pm 0.3$ & $1.3 \pm 0.3$ & $1.3 \pm 0.3$ \\
\hline LS mean \pm SE change & $0.03 \pm 0.01$ & $0.09 \pm 0.01$ & $0.10 \pm 0.01$ & $0.03 \pm 0.02$ & $0.12 \pm 0.02$ & $0.12 \pm 0.02$ \\
\hline \multirow[t]{2}{*}{ Median (IQR) percent change } & 3.2 & 7.3 & 9.5 & 3.9 & 9.2 & 9.7 \\
\hline & $(-6.0,13.6)$ & $(-2.6,19.6)$ & $(-0.7,20.0)$ & $(-4.7,11.8)$ & $(0.0,17.6)$ & $(-0.8,21.2)$ \\
\hline LS mean \pm SE percent change & $4.0 \pm 0.8$ & $9.2 \pm 0.7$ & $10.2 \pm 0.7$ & $3.6 \pm 1.4$ & $9.8 \pm 1.3$ & $10.8 \pm 1.4$ \\
\hline Difference versus PBO (95\% Cl) & & $5.2(3.1,7.3)$ & $6.1(4.1,8.2)$ & & $6.2(2.4,9.9)$ & $7.2(3.4,11.0)$ \\
\hline LDL-C/HDL-C, n & 444 & 609 & 601 & 118 & 137 & 129 \\
\hline Mean \pm SD baseline, $\mathrm{mol} / \mathrm{mol}$ & $2.6 \pm 1.1$ & $2.5 \pm 1.0$ & $2.4 \pm 0.9$ & $2.3 \pm 1.0$ & $2.2 \pm 0.9$ & $2.2 \pm 0.8$ \\
\hline LS mean \pm SE change & $-0.13 \pm 0.03$ & $-0.12 \pm 0.03$ & $-0.07 \pm 0.03$ & $-0.10 \pm 0.05$ & $-0.15 \pm 0.05$ & $-0.11 \pm 0.05$ \\
\hline \multirow[t]{2}{*}{ Median (IQR) percent change } & -6.8 & -5.4 & -1.5 & -4.4 & -3.3 & -7.3 \\
\hline & $(-19.3,9.3)$ & $(-19.0,10.9)$ & $(-16.3,14.1)$ & $(-19.8,12.8)$ & $(-17.4,7.8)$ & $(-21.9,11.8)$ \\
\hline LS mean \pm SE percent change & $-0.5 \pm 1.4$ & $-0.7 \pm 1.2$ & $1.3 \pm 1.2$ & $-1.4 \pm 2.3$ & $-4.2 \pm 2.2$ & $-1.2 \pm 2.3$ \\
\hline Difference versus PBO (95\% Cl) & & $-0.2(-3.8,3.4)$ & $1.8(-1.8,5.4)$ & & $-2.8(-9.1,3.4)$ & $0.2(-6.2,6.5)$ \\
\hline Non-HDL-C, n & 446 & 609 & 602 & 117 & 138 & 127 \\
\hline Mean \pm SD baseline, $\mathrm{mmol} / \mathrm{L}$ & $3.9 \pm 1.1$ & $3.8 \pm 1.1$ & $3.6 \pm 1.0$ & $3.5 \pm 1.2$ & $3.5 \pm 1.1$ & $3.5 \pm 1.1$ \\
\hline LS mean \pm SE change & $-0.04 \pm 0.04$ & $0.00 \pm 0.03$ & $0.10 \pm 0.03$ & $-0.09 \pm 0.07$ & $-0.02 \pm 0.06$ & $-0.02 \pm 0.06$ \\
\hline \multirow[t]{2}{*}{ Median (IQR) percent change } & -2.3 & -0.7 & 2.4 & -2.6 & 0.0 & 0.0 \\
\hline & $(-13.6,9.7)$ & $(-10.2,13.1)$ & $(-8.6,14.9)$ & $(-10.6,9.5)$ & $(-6.3,11.5)$ & $(-12.6,13.5)$ \\
\hline LS mean \pm SE percent change & $1.1 \pm 1.0$ & $2.6 \pm 0.9$ & $4.7 \pm 0.9$ & $-0.5 \pm 1.8$ & $0.8 \pm 1.7$ & $2.8 \pm 1.8$ \\
\hline Difference versus PBO (95\% Cl) & & $1.4(-1.3,4.1)$ & $3.6(0.8,6.3)$ & & $1.3(-3.6,6.2)$ & $3.3(-1.7,8.3)$ \\
\hline
\end{tabular}

LOCF, last observation carried forward; PBO, placebo; CANA, canagliflozin; SD, standard deviation; LS, least squares; SE, standard error; IQR, interquartile range; $\mathrm{Cl}$, confidence interval; LDL-C, low-density lipoprotein cholesterol; HDL-C, high-density lipoprotein cholesterol.

*All fasting plasma lipids parameters are reported for regardless of rescue medication.

smaller than those seen in other studies with generally younger patients $[9,10,12,14-16]$.

Body weight was reduced with both canagliflozin doses relative to placebo in patients $<65$ and $\geq 65$ years of age, with generally similar effects in the 2 age subsets. Canagliflozin was associated with greater reductions from baseline in systolic and diastolic BP relative to placebo in both age subsets; reductions in diastolic BP were numerically larger in patients $\geq 65$ years versus $<65$ years of age. The reductions in BP with canagliflozin were not associated with notable changes in pulse rate or incidence of AEs related to volume depletion in either age group. 
Canagliflozin 100 and $300 \mathrm{mg}$ were generally well tolerated in patients $<65$ and $\geq 65$ years of age. The incidence of overall AEs was similar across treatment groups in both age subsets, with no notable increase in patients $\geq 65$ years relative to those $<65$ years of age. Serious AEs and AEs leading to study discontinuation were slightly more common with canagliflozin $100 \mathrm{mg}$ relative to canagliflozin $300 \mathrm{mg}$ and placebo in patients $\geq 65$ years of age, with numerical differences not associated with any pattern in specific AEs. As previously observed [9-13], canagliflozin was associated with increased incidences of genital mycotic infections and osmotic diuresis-related AEs, with no notable differences observed between the 2 age subsets. The incidence of volume depletion-related AEs was low and similar with canagliflozin and placebo in patients $<65$ years of age; the incidence of these AEs was generally higher in patients $\geq 65$ years of age, with slightly higher rates with canagliflozin relative to placebo. In patients $<65$ years of age, the incidence of renal-related AEs was low but higher with canagliflozin $300 \mathrm{mg}$ relative to canagliflozin $100 \mathrm{mg}$ and placebo, while the incidence of these AEs was low and similar across groups in patients $\geq 65$ years of age. Canagliflozin was not associated with increased incidences of UTIs or documented or serious hypoglycaemia episodes in patients $\geq 65$ years of age. The relatively low risk of hypoglycaemia observed with canagliflozin when not used in combination with agents associated with hypoglycaemia (eg, insulin and sulphonylurea) is consistent with its mechanism of action, as canagliflozin lowers the $\mathrm{RT}_{\mathrm{G}}$ to approximately 4.4 to $5.0 \mathrm{mmol} / \mathrm{L}[8,17]$, above the usual threshold for hypoglycaemia of $3.9 \mathrm{mmol} / \mathrm{L}$. In this analysis, the number of patients on background AHAs associated with hypoglycaemia was small; in these patients, an increased incidence of documented hypoglycaemia was observed with canagliflozin in both age subsets, with no increase in severe events, consistent with previous studies of canagliflozin in patients on background insulin or sulphonylurea $[11,13,15,23]$. Overall, the safety profile of canagliflozin relative to placebo in this analysis was consistent with that seen in previous studies, including those in generally younger patient populations $[9,11,13-16]$. There was no consistent dose-related increase in the incidence of several AEs (eg, UTIs, genital mycotic infections, osmotic diuresisrelated AEs) in patients $<65$ or $\geq 65$ years of age.

Both canagliflozin doses were associated with increases in HDL-C and LDL-C, and no change in the LDL-C/ HDL-C ratio, relative to placebo. The changes in lipid parameters with canagliflozin were generally similar in patients $<65$ and $\geq 65$ years of age, and were consistent with previous observations in individual Phase 3 studies [9-16]. Similar changes in lipid parameters have been seen with other SGLT2 inhibitors [24,25]. The mechanism for the increase in LDL-C seen with canagliflozin is unknown.
In previous studies in which changes in apolipoprotein B (Apo B) were assessed, canagliflozin was associated with increases in Apo B that were smaller than those in LDL-C $[9,14]$.

Findings from this integrated analysis extend those from a previous study in older patients $\geq 55$ to $\leq 80$ years of age [11] by providing a direct comparison of the efficacy and safety of canagliflozin in patients $<65$ and $\geq 65$ years of age based on a larger, pooled patient population representing a broad and general population of patients with T2DM. A limitation of this analysis was the lack of prespecified statistical testing for comparisons between the age groups; in addition, the Phase 3 studies pooled in this report were not powered to evaluate statistical differences between age subgroups. However, 95\% CIs for the comparisons of canagliflozin 100 and $300 \mathrm{mg}$ relative to placebo within each age subset are reported. Assessments over a longer treatment period and including active comparators will be helpful in further defining the efficacy/ safety profile of canagliflozin relative to other available AHAs as treatment options for older patients with T2DM. Other issues that may impact the management of T2DM, such as self-management ability, cognitive function, need for carer support, and frailty [4,5], will also be important considerations in the selection of AHA treatment for older patients with T2DM.

\section{Conclusions}

Improvements in glycaemic control, body weight, and systolic BP seen with canagliflozin were generally consistent between younger ( $<65$ years of age) and older $(\geq 65$ years of age) patients. Moreover, there were no notable differences in the safety and tolerability profile of canagliflozin between these age subsets. Thus, these findings suggest that canagliflozin is an effective and generally well tolerated treatment option for older patients with T2DM.

\section{Additional file}

Additional file 1: List of institutional review boards (IRBs) and independent ethics committees (IECs) by study.

\footnotetext{
Abbreviations

AE: Adverse event; AHA: Antihyperglycaemic agent; ALT: Alanine aminotransferase; ANCOVA: Analysis of covariance; Apo B: Apolipoprotein B; BMI: Body mass index; BP: Blood pressure; bpm: beats per minute; CANA: Canagliflozin; Cl: Confidence interval; CV: Cardiovascular; eGFR: estimated glomerular filtration rate; FPG: Fasting plasma glucose; HDL-C: High-density lipoprotein cholesterol; IQR: Interquartile range; LDL-C: Low-density lipoprotein cholesterol; LOCF: Last observation carried forward; LS: Least squares; MedDRA: Medical Dictionary for Regulatory Activities; MET: Metformin; mITT: Modified intent-to-treat; PBO: Placebo; PIO: Pioglitazone; $\mathrm{RT}_{\mathrm{G}}$ : Renal threshold for glucose; SD: Standard deviation; SE: Standard error; SGLT2: Sodium glucose co-transporter 2;

SU: Sulphonylurea; T2DM: Type 2 diabetes mellitus; UGE: Urinary glucose excretion; ULN: Upper limit of normal; UTI: Urinary tract infection.
} 


\section{Competing interests}

AS has received lecture and/or advisory board fees from Takeda, Novartis, Eli Lilly and Company, and Merck Sharp \& Dohme. BB has served as investigator using research and grant support received by his institution from Janssen Research \& Development, LLC. SH has served on advisory boards for Sanofi-Aventis, Janssen, Novo Nordisk, Takeda, AstraZeneca, Bristol-Myers Squibb, Eli Lilly and Company, Boehringer Ingelheim; served as a speaker for Sanofi-Aventis, AstraZeneca, Bristol-Myers Squibb, Eli Lilly and Company, Boehringer Ingelheim, and Novo Nordisk; and has received research support from Sanofi-Aventis, Novo Nordisk, and Merck. UV, CM, AF, WS, KU, MD, and GM are current or former full-time employees of Janssen Research \& Development, LLC. CM is a holder of Johnson \& Johnson stock and stock options.

\section{Authors' contributions}

$A S, B B$, and $\mathrm{SH}$ contributed to the interpretation of data, and drafted, reviewed, and approved the manuscript. AF, WS, KU, MD, and GM contributed to the design and conduct of the analysis; the acquisition, analysis, and interpretation of data; and drafted, reviewed, and approved the manuscript. UV and CM contributed to the analysis and interpretation of the data, and drafted, reviewed, and approved the manuscript. All authors read and approved the final manuscript.

\section{Acknowledgements}

The studies described in this manuscript were sponsored by Janssen Research \& Development, LLC. The sponsor had a role in the study design and conduct, and in data collection, analysis, and interpretation. The authors prepared the report with editorial assistance funded by the sponsor. All authors had full access to study data, were responsible for the integrity of the data and the accuracy of the data analysis, and reviewed, edited, and approved the report for publication.

The authors thank all investigators, study teams, and patients for participating in this study. The authors acknowledge Gordon Law, PhD, of Janssen Research \& Development, LLC, for his contributions to the statistical analysis. Editorial support was provided by Kimberly Dittmar, PhD, of MedErgy, and was funded by Janssen Global Services, LLC. Canagliflozin has been developed by Janssen Research \& Development, LLC, in collaboration with Mitsubishi Tanabe Pharma Corporation.

\section{Author details}

'Luton \& Dunstable University Hospital; Bedfordshire and Hertfordshire Postgraduate Medical School, University of Bedfordshire, Putteridge Bury Campus, Hitchin Road, Luton LU2 8LE, UK. ${ }^{2}$ Atlanta Diabetes Associates, 77 Collier Rd. Suite 2080, Atlanta, GA 30309, USA. ${ }^{3}$ University of Western Ontario, 245-100 Collip Circle, UWO Research Park, London, Ontario N6G-4X8, Canada. ${ }^{4} J a n s s e n$ Research \& Development, LLC, 920 Route 202 South, Raritan NJ 08869, USA. ${ }^{5}$ Janssen Research \& Development, LLC, 1125

Trenton-Harbourton Road, Titusville NJ 08560, USA.

Received: 31 December 2013 Accepted: 10 April 2014 Published: 18 April 2014

\section{References}

1. Inzucchi SE, Bergenstal RM, Buse JB, Diamant M, Ferrannini E, Nauck M, Peters AL, Tsapas A, Wender R, Matthews DR: Management of hyperglycaemia in type 2 diabetes: a patient-centered approach. Position statement of the American Diabetes Association (ADA) and the European Association for the Study of Diabetes (EASD). Diabetologia 2012, 55:1577-1596.

2. Canadian Diabetes Association: Clinical Practice Guidelines. [http://guidelines.diabetes.ca/]

3. Booth GL, Kapral MK, Fung K, Tu JV: Relation between age and cardiovascular disease in men and women with diabetes compared with non-diabetic people: a population-based retrospective cohort study. Lancet 2006, 368:29-36.

4. International Diabetes Federation: Global guidelines for type 2 diabetes. [http://www.idf.org/sites/default/files/IDF-Guideline-for-Type-2-Diabetes.pdf].

5. Meneilly GS, Knip A, Tessier D: Canadian Diabetes Association 2013 Clinical Practice Guidelines for the Prevention and Management of
Diabetes in Canada: diabetes in the elderly. Can J Diabetes 2013, 37(suppl):S184-S190.

6. Bramlage P, Gitt AK, Binz C, Krekler M, Deeg E, Tschope D: Oral antidiabetic treatment in type-2 diabetes in the elderly: balancing the need for glucose control and the risk of hypoglycemia. Cardiovasc Diabetol 2012, 11:122.

7. Budnitz DS, Lovegrove MC, Shehab N, Richards CL: Emergency hospitalizations for adverse drug events in older Americans. N Engl J Med 2011, 365:2002-2012.

8. Rosenstock J, Aggarwal N, Polidori D, Zhao Y, Arbit D, Usiskin K, Capuano G, Canovatchel W, for the Canagliflozin DIA 2001 Study Group: Dose-ranging effects of canagliflozin, a sodium-glucose cotransporter 2 inhibitor, as add-on to metformin in subjects with type 2 diabetes. Diabetes Care 2012, 35:1232-1238

9. Stenlöf K, Cefalu WT, Kim K-A, Alba M, Usiskin K, Tong C, Canovatchel W, Meininger G: Efficacy and safety of canagliflozin monotherapy in subjects with type 2 diabetes mellitus inadequately controlled with diet and exercise. Diabetes Obes Metab 2013, 15:372-382.

10. Schernthaner G, Gross JL, Rosenstock J, Guarisco M, Fu M, Yee J, Kawaguchi M, Canovatchel W, Meininger G: Canagliflozin compared with sitagliptin for patients with type 2 diabetes who do not have adequate glycemic control with metformin plus sulfonylurea: a 52-week, randomized trial. Diabetes Care 2013, 36:2508-2515.

11. Bode B, Stenlöf K, Sullivan D, Fung A, Usiskin K: Efficacy and safety of canagliflozin treatment in older subjects with type 2 diabetes mellitus: a randomized trial. Hosp Pract 2013, 41:72-84.

12. Cefalu WT, Leiter LA, Yoon K-H, Arias P, Niskanen L, Xie J, Balis DA, Canovatchel W, Meininger G: Efficacy and safety of canagliflozin versus glimepiride in patients with type 2 diabetes inadequately controlled with metformin (CANTATA-SU): 52 week results from a randomised, double-blind, phase 3 non-inferiority trial. Lancet 2013, 382:941-950.

13. Yale JF, Bakris G, Cariou B, Yue D, David-Neto E, Xi L, Figueroa K, Wajs E, Usiskin K, Meininger G: Efficacy and safety of canagliflozin in subjects with type 2 diabetes and chronic kidney disease. Diabetes Obes Metab 2013, 15:463-473.

14. Lavalle-González F, Januszewicz A, Davidson J, Tong C, Qiu R, Canovatchel W, Meininger G: Efficacy and safety of canagliflozin compared with placebo and sitagliptin in patients with type 2 diabetes on background metformin monotherapy: a randomised trial. Diabetologia 2013, 56:2582-2592.

15. Wilding JP, Charpentier G, Hollander P, Gonzalez-Galvez G, Mathieu C, Vercruysse F, Usiskin K, Law G, Black S, Canovatchel W, Meininger G: Efficacy and safety of canagliflozin in patients with type 2 diabetes mellitus inadequately controlled with metformin and sulphonylurea: a randomised trial. Int J Clin Pract 2013, 67:1267-1282.

16. Stenlöf K, Cefalu WT, Kim KA, Jodar E, Alba M, Edwards R, Tong C, Canovatchel W, Meininger G: Long-term efficacy and safety of canagliflozin monotherapy in patients with type 2 diabetes inadequately controlled with diet and exercise: findings from the 52-week CANTATA-M study. Curr Med Res Opin 2014, 30:163-175.

17. Devineni D, Morrow L, Hompesch M, Skee D, Vandebosch A, Murphy J, Ways K, Schwartz S: Canagliflozin improves glycemic control over 28 days in subjects with type 2 diabetes not optimally controlled on insulin. Diabetes Obes Metab 2012, 14:539-545.

18. Polidori D, Sha S, Ghosh A, Plum-Morschel L, Heise T, Rothenberg P: Validation of a novel method for determining the renal threshold for glucose excretion in untreated and canagliflozin-treated subjects with type 2 diabetes mellitus. J Clin Endocrinol Metab 2013, 98:E867-E871.

19. Sinclair A, Morley JE, Rodriguez-Manas L, Paolisso G, Bayer T, Zeyfang A, Bourdel-Marchasson I, Vischer U, Woo J, Chapman I, Dunning T, Meneilly G, Rodriguez-Saldana J, Gutierrez Robledo LM, Cukierman-Yaffe T, Gadsby R, Schernthaner G, Lorig K: Diabetes mellitus in older people: position statement on behalf of the International Association of Gerontology and Geriatrics (IAGG), the European Diabetes Working Party for Older People (EDWPOP), and the International Task Force of Experts in Diabetes. J Am Med Dir Assoc 2012, 13:497-502.

20. Sha S, Devineni D, Ghosh A, Polidori D, Chien S, Wexler D, Shalayda K, Demarest K, Rothenberg P: Canagliflozin, a novel inhibitor of sodium glucose co-transporter 2, dose dependently reduces calculated renal threshold for glucose excretion and increases urinary glucose excretion in healthy subjects. Diabetes Obes Metab 2011, 13:669-672. 
21. Liang Y, Arakawa K, Ueta K, Matsushita Y, Kuriyama C, Martin T, Du F, Liu Y, Xu J, Conway B, Conway J, Polidori D, Ways K, Demarest K: Effect of canagliflozin on renal threshold for glucose, glycemia, and body weight in normal and diabetic animal models. PLOS ONE 2012, 7:e30555.

22. Polidori D, Sakai M, Devineni D: Exposure-response modeling of canagliflozin effects on the renal glucose threshold in subjects with type 2 diabetes (T2DM) [abstract]. Diabetes 2011, 60(suppl 1):A294.

23. Rosenstock J, Davies M, Dumas R, Desai M, Alba M, Capuano G, Meininger G: Effects of canagliflozin added on to basal insulin +/- other antihyperglycemic agents in type 2 diabetes [abstract]. Diabetes 2013, 62(suppl 1):A280.

24. Summary of Product Characteristics: Forxiga $5 \mathrm{mg}$ and $10 \mathrm{mg}$ film-coated tablets. Middlesex, United Kingdom: Bristol-Myers Squibb/AstraZeneca EEIG; 2012.

25. Hach T, Gerich JE, Salsali A, Kim G, Hantal S, Woerle HJ, Broedl UC: Empagliflozin improves glycemic parameters and cardiovascular risk factors in patients with type 2 diabetes (T2DM): pooled data from four pivotal phase III trials [abstract]. Diabetes 2013, 62(suppl 1):LB19.

doi:10.1186/1472-6823-14-37

Cite this article as: Sinclair et al:: Efficacy and safety of canagliflozin compared with placebo in older patients with type 2 diabetes mellitus: a pooled analysis of clinical studies. BMC Endocrine Disorders 2014 14:37.

\section{Submit your next manuscript to BioMed Central and take full advantage of:}

- Convenient online submission

- Thorough peer review

- No space constraints or color figure charges

- Immediate publication on acceptance

- Inclusion in PubMed, CAS, Scopus and Google Scholar

- Research which is freely available for redistribution 